\title{
The Meaning of Weight Change in Older Age in Relational to Function and Mortality
}

Shahar DR* and Robinson E

Department of Public Health, The S. Daniel Abraham

International Center for Health and Nutrition, Ben-

Gurion University of the Negev, Israel

*Correspondling author: Danit R Shahar, The S.

Daniel Abraham International Center for Health and

Nutrition, Department of Public Health, Faculty of Health

Sciences, Ben-Gurion University of the Negev, Beer-

Sheva, Israel

Received: December 04, 2017; Accepted: December 12, 2017; Published: December 19, 2017

\section{Editorial}

Although populations of all ages are at risk for the complications of excess weight, its effects on the elderly population is attenuated [13]. Among the elderly, weight gain in itself bears less risk than weight loss. Aging is associated with physiologic changes, chronic disease, polypharmacy, and psychosocial changes; therefore older adults have an increased risk of under nutrition compared with younger age groups [4].

A large meta-analysis by Flegal et al. [5] including 97 studies $[\mathrm{n}=2.88$ million individuals] showed a significant decrease in all cause mortality for the overweight 65 -y age group. Another meta-analysis of 32 studies [ $\mathrm{n}=197,940$ individuals] concluded that being overweight among adults over the age of 65 was not found to be associated with an increased risk of mortality; however, there was an increased risk for those at the lower end of the recommended BMI range for adults [3].

A study based on the Cardiovascular Health Study data showed increased risk for ADL impairment and mobility limitations in individuals with higher starting weight, but no risk was found to be associated with weight gain. Moreover, the same study showed a significant increase in risk associated with weight loss [2]. In fact, for some forms of disease, obesity may even lower the risk for mortality. This effect has become known as the "obesity paradox" [6,7]. This relationship may be partly explained by a protective effect of lean body mass [8-13]. The relationship between BMI and mortality rate can be described by a " $U$ shaped curve", meaning the lowest mortality rates are observed among individuals with higher-normal range and slightly "overweight" level of BMI $[8,13,14]$. The mortality rate of individuals with low BMI increases with age [15]. Further analysis shows that unintentional weight loss leads to higher mortality rates and more disability than intentional weight loss [8]. This might be due to unintentional weight loss being a surrogate for a subclinical or undiagnosed disease.

Along with weight changes over time, even older individuals whose weight is stable gradually change their body composition by losing lean body mass and gaining fat mass. This shift in body composition is exaggerated when there is net weight loss [9]. Low lean body mass that manifests in extreme situations as sarcopenia (muscle loss) was associated with increased risk of disability and frailty $[10,11]$. Several studies performed analysis of changes in weight and their effects using trajectories. Arnold, et al. [2] used each participant's past data to designate a pattern of change in weight. When using stable weight as a reference they found that weight cycling holds the highest risk for mortality (Hazard ratio (HR) 2.20 95\% CI:[1.83, 2.63] - females; HR 1.66 95\% CI:[1.38, 2.00] - males) as well as mobility disability (HR 1.44 95\% CI: [1.25, 1.67] - females; 1.36 95\% CI:[1.18, 1.58] - males). A similar approach was used by Strand berg et al. in 2013: [12] the participants were stratified into 4 groups according to the difference between 2 BMI measurements taken 26 years apart. They found mortality rates to be higher among those who were either constantly overweight (30\% higher) or lost weight ( $80 \%$ higher) compared to those who were consistently at normal weight. Interestingly, men who had gained weight after midlife had similar mortality rates as the reference group [12]. A recent publication based on the Health $\mathrm{ABC}$ study data used group-based trajectory modeling to determine BMI trajectories and their association with change in lean mass and physical function [13]. This was performed using group-based trajectory modeling. They found 4 trajectories for both men and women. They all showed decline and did not differ greatly in the rate of decline. They concluded that the weight and health of a person before entering older age probably has a greater impact on outcomes than the trend over time.

Weight change has been recommended [14] as the best diagnostic tool for malnutrition in the elderly. It is also a highly powerful tool for monitoring nutritional risk in the elderly. However, its impact on a wide range of outcomes differs by patient characteristics and heath status. As mentioned above, part of the confusion is attributed to differences in body composition associated with weight change. Namely, how do the different compartments change individually in the face of the recorded weight change? So far the best predictor for lower risk is the starting weight recorded when one is considered "elderly". Persons of both genders who reach their older age with some excess weight are doing better in regard to various functional outcomes. Yet, It remains to be defined how weight change, be it combined or compartment-specific, interacts with variables such as gender, ethnic group, or different medical status. One factor limiting the value of weight as a predictor is that weight as an isolated measure falls short of reflecting diet quality; and is reliable only as a quantitative measure of caloric intake. Thus weight may capture caloric intake but not diet quality. Consequently, weight gain may have a positive impact on outcomes in some but not in others who may consume diets with different food composition and diet quality.

In summary, weight is a highly available inexpensive and highly reliable measure to be used in nutritional assessment in the old. 
Nonetheless, it should be taken with caution when issues such as body composition, specific nutrients, and diet quality are in question.

\section{References}

1. Adams KF, Schatzkin A, Harris TB, Kipnis V, Mouw T, Barbash RB, et al Overweight, obesity, and mortality in a large prospective cohort of persons 50 to 71 years old. N Engl J Med. 2006; 355: 763-778.

2. Arnold AM, Newman AB, Cushman M, Ding J, Kritchevsky S. Body weigh dynamics and their association with physical function and mortality in older adults: the Cardiovascular Health Study. Journals of Gerontology Series A Biomedical Sciences and Medical Sciences. 2009; 65: 63-70.

3. Winter JE, MacInnis RJ, Wattanapenpaiboon N, Nowson CA. BMI and allcause mortality in older adults: a meta-analysis. The American Journal of Clinical Nutrition. 2014.

4. Alley DE, Metter EJ, Griswold ME, Harris TB, Simonsick EM, Longo DL, et al. Changes in weight at the end of life: characterizing weight loss by time to death in a cohort study of older men. Am J Epidemiol. 2010; 172: 558-565.

5. Flegal KM, Kit BK, Orpana H, Graubard BI. Association of all-cause mortality with overweight and obesity using standard body mass index categories: a systematic review and meta-analysis. JAMA. 2013; 309: 71-82.

6. Jahangir E, De Schutter A, Lavie CJ. Low weight and overweightness in older adults: risk and clinical management. ProgCardiovasc Dis. 2014; 57: 127 133

7. De Schutter A, Lavie CJ, Kachur S, Patel DA, Milani RV. Body composition and mortality in a large cohort with preserved ejection fraction: untangling the obesity paradox. Elsevier. 2014.
8. Lee JS, Kritchevsky SB, Harris TB, Tylavsky F, Rubin SM, Newman AB. Short-term weight changes in community-dwelling older adults: the Health Aging, and Body Composition Weight Change Substudy. Am J ClinNutr. 2005; 82: 644-650.

9. Newman AB, Lee JS, Visser M, Goodpaster BH, Kritchevsky SB, Tylavsky FA, et al. Weight change and the conservation of lean mass in old age: the Health, Aging and Body Composition Study. Am J ClinNutr. 2005; 82: $872-$ 878.

10. Bales CW, Buhr GT. Body mass trajectory, energy balance, and weight loss as determinants of health and mortality in older adults. Obes Facts. 2009; 2: 171-178.

11. Bales CW, Ritchie CS. Sarcopenia, Weight Loss, and Nutritional Frailty in the Elderly. Annu Rev Nutr. 2002; 22: 309-323.

12. Strandberg TE, Stenholm S, Strandberg AY, Salomaa VV, Pitkälä KH, Tilvis RS. The "obesity paradox," frailty, disability, and mortality in older men: a prospective, longitudinal cohort study. Am J Epidemiol. 2013; 178: 1452-160.

13. Reinders I, Murphy RA, Martin KR, Brouwer IA, Visser M, White DK, et al. Body mass index trajectories in relation to change in lean mass and physical function: The Health, Aging and Body Composition Study. J Am Geriatr Soc. 2015; 63: 1615-1621.

14. Guerra RS, Fonseca I, Sousa AS, Jesus A, Pichel F, Amaral TF. ESPEN diagnostic criteria for malnutrition - A validation study in hospitalized patients. Clinical Nutrition.
Austin J Nutri Food Sci - Volume 5 Issue 2 - 2017

ISSN : 2381-8980 | www.austinpublishing group.com

Shahar et al. (C) All rights are reserved
Citation: Shahar DR and Robinson E. The Meaning of Weight Change in Older Age in Relational to Function and Mortality. Austin J Nutri Food Sci. 2017; 5(2): 1091. 